Clinical microbiology

\title{
Qualitative, quantitative and genotypic evaluation of Aggregatibacter actinomycetemcomitans and Fusobacterium nucleatum isolated from individuals with different periodontal clinical conditions
}

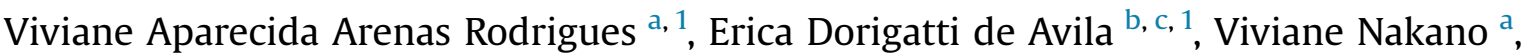 \\ Mario Julio Avila-Campos a, * \\ ${ }^{a}$ Anaerobe Laboratory, Department of Microbiology, Institute of Biomedical Sciences, University of Sao Paulo - USP, Av. Prof. Lineu Prestes, 1374, Sao Paulo, \\ SP, Brazil \\ ${ }^{\mathrm{b}}$ Postdoctoral Research Fellow, Department of Dental Materials and Prosthodontics, School of Dentistry of Araraquara, Sao Paulo State University - UNESP, \\ Rua Humaita, 1680, Araraquara, SP, Brazil \\ ${ }^{\mathrm{c}}$ Department of Biomaterials, Radboud University Medical Center, Philips van Leydenlaan 25, Nijmegen, the Netherlands
}

\section{A R T I C L E I N F O}

\section{Article history:}

Received 24 December 2017

Received in revised form

26 April 2018

Accepted 28 May 2018

Available online 29 May 2018

Handling Editor: Elisabeth Nagy

\section{Keywords:}

Aggregatibacter actinomycetemcomitans

Fusobacterium nucleatum

Oral microbiology

Periodontal disease

Bacterial typing

\begin{abstract}
A B S T R A C T
Aggregatibacter actinomycetemcomitans and Fusobacterium nucleatum are strongly associated with periodontitis, and their evaluations are relevant to understand their role in the etiology and progression of periodontal diseases. In this study, the qualitative and quantitative detection of $A$. actinomycetemcomitans and $F$. nucleatum, as well as their genetic diversity, were evaluated in individuals with gingivitis, chronic periodontitis and periodontally healthy. In addition, the biotyping, serotyping, and prevalence of the $l t x$ and $c d t$ genes in A. actinomycetemcomitans were also determined. Subgingival biofilms obtained from gingivitis (70), periodontitis (75) and healthy (95) individuals were analyzed by cultures and PCR. Bacterial typing and presence of $l t x$ and $c d t$ genes in A. actinomycetemcomitans were also verified. DNA from A. actinomycetemcomitans and F. nucleatum was detected respectively, in $65.7 \%$ and $57.1 \%$ of gingivitis, $80 \%$ and $68 \%$ of periodontitis, and $57.8 \%$ and $37.8 \%$ of healthy. A. actinomycetemcomitans from gingivitis were biotypes I, II, IV, V, and X, and serotypes a, c, and e. In periodontitis, biotypes II, VI, and X, and serotypes a, b, and c were found. In healthy subjects, biotypes II and X, and serotypes b and c were found. The LTX and ItxA were observed in strains from gingivitis and periodontitis pockets. Subsequently, our data also showed no direct relationship between ltxA gene expression and leukotoxin gene 530-bp presence. On the other hand, $c d t$ gene predominated during the inflammatory disease process. Our results strongly support a role of A. actinomycetemcomitans and $F$. nucleatum in advanced stage of periodontal disease.
\end{abstract}

(C) 2018 Elsevier Ltd. All rights reserved.

\section{Introduction}

Periodontal disease expression involves intrinsic interactions of the biofilm with the host's immune inflammatory response and subsequent alterations in bone and connective tissue homeostasis $[1,2]$. Although this complex disease is dependent on contexts, such as age [3], oral hygiene habits [4], and acquired behavioral factors, periodontal bacteria are considered to be the most important etiologic factors that are able to initiate the inflammatory response [5].

Among the oral pathogenic bacteria, Aggregatibacter actinomycetemcomitans, a Gram-negative bacterium, is particularly known to be involved with aggressive and chronic periodontal disease [5-9]. The drastic inflammatory response is a

\footnotetext{
* Corresponding author. Anaerobe Laboratory, Department of Microbiology, University of Sao Paulo - USP, Av. Prof. Lineu Prestes 1374, 05508-900, São Paulo, SP, Brazil. E-mail address: mariojac@usp.br (M.J. Avila-Campos).

1 These authors contributed equally to this work.
} 
consequence of interactions between virulence factors from A. actinomycetemcomitans and the host's cells, mainly, fibroblasts and epithelium cells. To this date, seven serotypes of A. actinomycetemcomitans were identified [10], of which, serotypes a, b and c are detected most frequently in periodontal sites [11,12]. Interestingly, in a recent report, it was found that there is a high prevalence of strains entirely lacking serotype $b$ of A. actinomycetemcomitans from deep pockets with progressive periodontitis [13], contradicting previous outcomes. These findings suggest a potential difference in subgingival colonization or the antigenic composition of these pathogens depending on the geographical regions from different individuals populations [14]. Among the proteins expressed by A. actinomycetemcomitans, leukotoxin is considered to be the major toxic virulent factor [15]. Its participation in periodontal disease progression is due to the capacity to activate and intensify bone resorption by caspase- 1 stimulation in human monocytes/macrophages. Although all A. actinomycetemcomitans strains display the ltx gene, which is responsible to codify leukotoxin, variances in the $l t x$ region might affect the protein expression among individual strains [16]. Another virulence factor involved in the pathogenesis of periodontal diseases is cytolethal-distending toxins (CDTs) [17]. This protein targets a wide spectrum of eukaryotic cells, including fibroblasts and $\mathrm{T}$ lymphocytes [18], and induces RANK L expression to further promote osteoclastogenesis. Similar to leukotoxin, the CDT expression can also vary among strains of A. actinomycetemcomitans. Furthermore, the presence of $c d t$ genes may explain why some individuals are carriers and why there is an increased prevalence of A. actinomycetemcomitans associated with periodontitis depending on the geographical localization.

Another important Gram-negative bacterium involved with periodontal disease pathogenesis is Fusobacterium nucleatum $[19,20]$. This bacterial species is known to coaggregate with early and late colonizers by its proteins and receptors available in the out membrane, therefore contributing to periodontal disease progression [ 21 ]. In this context, the adhesins RadD and Fap2 were identified as two important virulence factors [ 22 ] that have binding properties for Gram-positive species and Porphyromonas gingivalis, respectively. Studies have shown that $F$. nucleatum, an anaerobic bacterium, is able to survive in high proportions of oxygen. This particular property may explain why fusobacteria are found in both healthy and diseased sites. Thus, $F$. nucleatum can have an important indirect role in the etiology of periodontal diseases by supporting the growth of some pathogenic bacteria, such as $P$. gingivalis, and possibly other oral anaerobes in oxygenated and $\mathrm{CO}_{2}$-depleted environments [ 23 ]. The multiple roles and complexity of $F$. nucleatum delineate it as an important microorganism involved in periodontal disease pathogenesis.

Because $A$. actinomycetemcomitans and $F$. nucleatum produce endogenous infections and are strongly associated with periodontitis, their evaluations are relevant to understand their role in the etiology, development and progression of periodontal diseases. Therefore, the purpose of this study was to detect A. actinomycetemcomitans and $F$. nucleatum, as well as their genetic diversity, in Brazilian individuals with gingivitis, chronic periodontitis and periodontally healthy subjects. In addition, the biotyping, serotyping, and prevalence of the $l t x$ and $c d t$ genes in A. actinomycetemcomitans were also determined. The null hypothesis established here is that periodontal conditions are related with the prevalence of $A$. actinomycetemcomitans and F. nucleatum. In an attempt to help understand carriage and disease processes, such microbiological data may also contribute to better microbial characterization and add the knowledge of the global distribution of both pathogenic bacteria.

\section{Materials and methods}

\subsection{Study design}

A cross-sectional study was performed in the Clinic of Periodontology, Dental School, at the University of Sao Paulo. Two hundred forty individuals between 20- and 60-years-old with at least 14 teeth were included. On the other hand, as exclusion criteria, this study did not select individuals who received antibiotic prophylaxis within the last 6 months before analysis for dental examination, had uncontrolled systemic diseases, were immunologically compromised, had prior periodontal treatment, were diagnosed with gingivitis or chronic periodontitis three months before the beginning of the study, were smokers, had edentulous or had prosthetics.

All individuals were informed about the study design and procedures and signed informed consent forms. The ethical principles were conducted consistent with the Declaration of Helsinki and the design was approved by the Ethics in Human Research Committee of the Institute of Biomedical Sciences (Process No. 910/CEP).

\subsection{Selected population and periodontal examination}

The individuals were assigned to three groups. Group I (control): 95 subjects with a healthy periodontium, attached gingivae dotted with a pink coral color, no bleeding on probing, and a probing depth $\leq 3 \mathrm{~mm}$; Group II: 70 individuals displaying clinical signs of gingivitis with gingival inflammation, light red erythema, loss of dotted surface (change in the texture of the gum surface), gingival recession without alveolar bone loss and a probing depth $\leq 3 \mathrm{~mm}$; and Group III: 75 individuals displaying chronic periodontitis with clinical and radiographic signs of bone loss, mild or moderately swollen gums, flat or shaped craters papillae, gingival spontaneous bleeding by probing, change of the gingival staining, tooth mobility and a probing depth $\geq 5 \mathrm{~mm}$.

A single trained examiner performed periodontal examination. The probing depth and gingival recession were measured and used to determine the clinical attachment level. The measures were made from six sites per tooth (mesio-vestibular, vestibular, distovestibular, meso-lingual, lingual and disto-lingual), excluding the third molars. The presence of supragingival biofilm and bleeding on probing were also recorded using the visible plaque and gingival plaque index, respectively.

\subsection{Sample collection, bacterial isolation and DNA extraction}

Prior to subgingival sampling, the supragingival biofilm was removed from the surfaces of the affected teeth with curettes. Mesio-buccal root of maxillary first permanent molars or central incisors were selected from healthy and subjects with gingivitis. Subgingival samples were collected from the deepest pockets of individuals with chronic periodontal disease. Then, two sterile paper points (No. 30-Dentsply, Ind Co Ltd, RJ, Brazil) were placed on the apical portion of the periodontal pocket or gingival crevice for $60 \mathrm{~s}$ and were then transported immediately to the laboratory in VMGA III medium [ 24 ]. Each clinical sample was washed twice with sterile Milli-Q water at $12,000 \mathrm{rpm}$ for $10 \mathrm{~min}$ and the pellet re-suspended in Milli-Q water [ 25 ].

Subgingival samples for assessment of genotype evaluation were dispersed by vortex, and aliquots of $0.1 \mathrm{~mL}$ from preestablished dilutions $\left(10^{-1}\right.$ to $\left.10^{-5}\right)$ were plated in duplicate onto selective trypticase soy-serum-bacitracin-vancomycin agar prior to further processing. After $72 \mathrm{~h}$ of incubation in anaerobic conditions $\left(90 \% \mathrm{~N}_{2}+10 \% \mathrm{CO}_{2}\right)$ at $37^{\circ} \mathrm{C}$, colonies of $A$. actinomycetemcomitans and $F$. nucleatum were identified using different approaches: 
stereoscopic microscope, Gram staining, catalase production and fermentation of carbohydrates according to standardized methods [ 26,27].

Total bacterial DNA from subgingival samples was isolated using a phenol-chloroform method [ 30 ] and stored at $-80^{\circ} \mathrm{C}$ until use. The concentration of DNA was determined with a UV spectrophotometer $\left(A_{260}=1.8\right.$, and $\left.A_{280} \mathrm{~nm}=2.0\right)$. Then, the DNA integrity was confirmed by loading $10 \mu \mathrm{L}$ of each DNA sample in a $1 \%$ agarose gel before use.

\subsection{Biotyping and serotyping of A. actinomycetemcomitans strains}

The differentiable physiologic characteristics of A. actinomycetemcomitans were evaluated for biotyping based on the fermentation of dextrin, maltose, mannitol, and xylose [ 27 ]. The distinct variation of serotypes within bacterial species was determined by multiplex PCR with specific primers (Supplemental data - Table 1) [ 28 ]. Briefly, cycling conditions were programmed for 1 cycle at $94^{\circ} \mathrm{C}$ for $5 \mathrm{~min}$ followed by 30 cycles of $94^{\circ} \mathrm{C}$ for $30 \mathrm{~s}$, $52{ }^{\circ} \mathrm{C}$ for $1 \mathrm{~min}$ and $72{ }^{\circ} \mathrm{C}$ for $1 \mathrm{~min}$. After the last amplification samples were incubated at $72^{\circ} \mathrm{C}$ for $5 \mathrm{~min}$ to fill in the protruding ends of newly synthesized PCR products. DNA from A. actinomycetemcomitans ATCC 29523 (serotype a), A. actinomycetemcomitans (serotype b), A. actinomycetemcomitans ATCC 33384 (serotype c), and A. actinomycetemcomitans CU 1000 (serotype f) were used as positive controls. The specific segments of DNA were analyzed using electrophoresis in $1 \%$ agarose gels, and images were digitally recorded using the Molecular Imager Gel Documentation system (Kodak Digital System DC-120).

\subsection{Detection of the ltx and cdt genes in A. actinomycetemcomitans}

PCR assays were performed using specific primers (Supplemental data - Table 1) [6,14,17, 29 ]. Amplifications were performed in volumes of $25 \mu \mathrm{L}$ containing 10 X PCR buffer, $50 \mathrm{mM}$ $\mathrm{MgCl}_{2}, 0.2 \mathrm{mM}$ dNTP, $0.4 \mu \mathrm{M}$ each primer, $0.5 \mathrm{U}$ Platinum Taq DNA polymerase, and $1 \mathrm{ng}$ DNA. The thermocycler was programmed for $94{ }^{\circ} \mathrm{C}(5 \mathrm{~min})$ followed by 30 cycles of $94^{\circ} \mathrm{C}(1 \mathrm{~min})$, $50{ }^{\circ} \mathrm{C}-65^{\circ} \mathrm{C}(1 \mathrm{~min}), 72^{\circ} \mathrm{C}(1 \mathrm{~min})$, and then $72^{\circ} \mathrm{C}(5 \mathrm{~min})$ to allow DNA extension. Ultrapure water instead of DNA was used as a negative control. PCR products were analyzed as mentioned above.

\subsection{Bacterial detection by PCR}

The PCR methodology used here was carried out as described in a previously published protocol [ 30 ]. The specific primers
(Supplemental data - Tables 1 and 2) [6,14,17, 28-31 ] were used for PCR amplification of each bacterial species (A. actinomycetemcomitans and $F$. nucleatum). The final concentrations for a $25-\mu \mathrm{l}$ PCR reaction are described in item 2.5. The thermal cycling conditions were programmed to 1 cycle of $94^{\circ} \mathrm{C}$ ( $5 \mathrm{~min}$ ) and 30 cycles of $94^{\circ} \mathrm{C}(30 \mathrm{~s}), 56^{\circ} \mathrm{C}(30 \mathrm{~s})$ and $72^{\circ} \mathrm{C}(30 \mathrm{~s})$ for A. actinomycetemcomitans, and for $F$. nucleatum, 1 cycle of $94^{\circ} \mathrm{C}$ (5 min) and 30 cycles of $94^{\circ} \mathrm{C}(30 \mathrm{~s}), 40{ }^{\circ} \mathrm{C}(30 \mathrm{~s})$ and $72{ }^{\circ} \mathrm{C}(30 \mathrm{~s})$; and 1 cycle of $72^{\circ} \mathrm{C}(5 \mathrm{~min})$ for final extension of the DNA were used. DNA from reference strains of $A$. actinomycetemcomitans ATCC 29523 and F. nucleatum ATCC 25586 served as positive controls while an ultrapure water template was used as background controls. The specific segments of DNA were analyzed by electrophoresis in $1 \%$ agarose gels, as mentioned above.

\subsection{Quantitative bacterial detection by $q P C R$ assays}

Initially, standard curves were generated by diluting the template control into a ten-fold dilution series. The amplification efficiency of the qPCR was based on the standard curve of distinct reference strains: A. actinomycetemcomitans ATCC 29523, F. nucleatum ATCC 25586, Actinomyces israelii ATCC 12102, Dialister pneumosintes ATCC 33048, Enterococcus faecalis ATCC 29212, Porphyromonas gingivalis ATCC 33277, Porphyromonas endodontalis ATCC 35406, Prevotella intermedia ATCC 25611, Prevotella nigrescens ATCC 33563, Tannerella forsythia ATCC 43037, and Treponema denticola ATCC 35405. The slope of the DNA standard curves was calculated by linear regression for each dilution using a system program Rotor Gene 6000 (Rotor Gene Series Software 1.7). The reaction efficiency was indicated by genomic copies of each bacterial species. Briefly, DNA quantification was determined using a SYBR Green system in a total of $20 \mu \mathrm{L}$, including 2X PCR Master Mix (Promega, Madison, USA) and $100 \mathrm{mM}$ species-specific primers (Supplemental data Table 3) [ 32-38 ]. The thermal cycler was programmed as follows for A. actinomycetemcomitans: 1 cycle of $95^{\circ} \mathrm{C}$ ( $\left.2 \mathrm{~min}\right), 40$ cycles of $95^{\circ} \mathrm{C}(45 \mathrm{~s}), 60^{\circ} \mathrm{C}(2 \mathrm{~min})$ and $56^{\circ} \mathrm{C}(2 \mathrm{~min})$ to F. nucleatum. For the other bacteria, we used annealing temperatures of $60^{\circ} \mathrm{C}$ ( $2 \mathrm{~min}$ ) for $P$. gingivalis, $P$. endodontalis, $T$. forsythia and $E$. faecalis; $55^{\circ} \mathrm{C}(2 \mathrm{~min})$ for $P$. intermedia and D. pneumosintes; $56^{\circ} \mathrm{C}(2 \mathrm{~min})$ for $P$. nigrescens; $59^{\circ} \mathrm{C}(2 \mathrm{~min})$ for T. denticola; and $50^{\circ} \mathrm{C}$ ( $\left.2 \mathrm{~min}\right)$ for A. israelii.

All amplification reactions were performed in triplicate in a thermal cycler Rotor Gene 6000 (Corbett Life Science, Mortlake, New South Wales, Australia). A dissociation curve (melting curve) was obtained to determine the primer specificity. A Master Mix without DNA served as a negative control.

Table 1

Demographic data of patients with gingivitis, chronic periodontitis and healthy. $p<0.001$.

\begin{tabular}{|c|c|c|c|}
\hline \multirow{2}{*}{ Characteristics } & \multicolumn{3}{|c|}{ Patients (No.) } \\
\hline & Gingivitis (70) & Chronic periodontitis (75) & Healthy (95) \\
\hline $\operatorname{Sex}(M / F)$ & $26 / 44$ & $38 / 37$ & $33 / 62$ \\
\hline Age in years & $37.0 \pm 13.6(34.5)$ & $46.5 \pm 9.0(47.0)$ & $29.9 \pm 9.7(27.0)$ \\
\hline \multicolumn{4}{|l|}{ Mean \pm SD (Median) } \\
\hline Alcohol consumption (\%) & $2(2.9)$ & $1(1.3)$ & $1(1.1)$ \\
\hline Tobacco consumption (\%) & $3(4.3)$ & $2(2.67)$ & $0(0.0)$ \\
\hline Probing depth (PD) & $2.9 \pm 0.3(3.0)$ & $5.9 \pm 0.8(6.0)$ & $1.7 \pm 0.6(2.0)$ \\
\hline \multicolumn{4}{|l|}{ Mean \pm SD (Median) } \\
\hline Visible plaque sites (\%) & $41.75 \pm 11.70$ & $46.21 \pm 10.20$ & $20.40 \pm 11.02$ \\
\hline Bleeding on probing & $41.30 \pm 2.20$ & $35.78 \pm 0.53$ & $11.40 \pm 1.22$ \\
\hline Bone loss & $42.8 \pm 2.33$ & $40.05 \pm 2.03$ & $0.85 \pm 0.23$ \\
\hline Tooth mobility & $20.02 \pm 1.56$ & $27.51 \pm 1.11$ & $1.01 \pm 0.13$ \\
\hline Gingival edema & $39.34 \pm 2.41$ & $37.53 \pm 1.15$ & $8.22 \pm 2.01$ \\
\hline
\end{tabular}

M/F: Male/Female. PD: Probing depth (in mm).

SD: Standard deviation.

Kruskal-Wallis test: $p<0.05$ values were considered statistically significant. 
Table 2

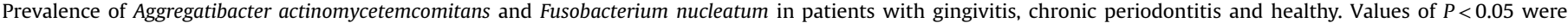
considered statistically significant values by the Kruskal-Wallis test.

\begin{tabular}{|c|c|c|c|c|c|c|c|c|}
\hline \multirow[t]{3}{*}{ Bacteria } & \multirow[t]{3}{*}{ Clinical group (No.) } & \multicolumn{2}{|c|}{ Culture } & \multicolumn{2}{|c|}{$\begin{array}{l}\text { Conventional } \\
\text { PCR }\end{array}$} & \multicolumn{2}{|c|}{ Real-time PCR } & \multirow[t]{3}{*}{$p$ values } \\
\hline & & \multicolumn{2}{|c|}{ Positives samples } & \multicolumn{2}{|c|}{$\begin{array}{l}\text { Positives } \\
\text { samples }\end{array}$} & \multicolumn{2}{|c|}{ Positive samples } & \\
\hline & & No. & $\%$ & No. & $\%$ & No. & $\%$ & \\
\hline \multirow[t]{3}{*}{ Aggregatibacter actinomycetemcomitans } & Gingivitis (70) & 2 & 2.8 & 46 & 65.7 & 50 & 71.4 & \multirow{3}{*}{$<0.002$} \\
\hline & Periodontitis (75) & 4 & 5.3 & 60 & 80.0 & 69 & 92.0 & \\
\hline & Healthy (95) & 5 & 5.26 & 55 & 57.8 & 62 & 65.2 & \\
\hline \multirow[t]{3}{*}{ Fusobacterium nucleatum } & Gingivitis (70) & 13 & $18.6^{\mathrm{b}}$ & 40 & 57.1 & 52 & 74.2 & \multirow{3}{*}{$<0.001$} \\
\hline & Periodontitis (75) & 20 & $26.6^{\mathrm{b}}$ & 51 & 68.0 & 68 & 90.6 & \\
\hline & Healthy (95) & 19 & $20^{\mathrm{b}}$ & 36 & 37.8 & 49 & 51.5 & \\
\hline
\end{tabular}

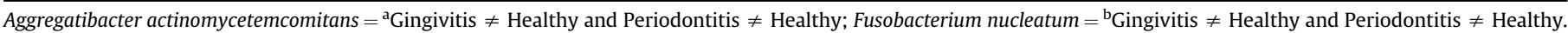

\subsection{Typing A. actinomycetemcomitans and F. nucleatum by arbitrarily primed $A P-P C R$}

Five arbitrary primers (Supplemental data - Table 1) were used for bacterial typing. DNA amplifications were performed in final volumes of $25 \mu \mathrm{L}$, as described in item 2.5. Thermal cycling parameters were initiated with a 5 -min denaturation at $94^{\circ} \mathrm{C}$, followed by 30 cycles of $94^{\circ} \mathrm{C}$ for $1 \mathrm{~min}, 34^{\circ} \mathrm{C}$ for $1 \mathrm{~min}, 72^{\circ} \mathrm{C}$ for 2 min and 1 cycle of $72^{\circ} \mathrm{C}$ for 5 min to final extension of the DNA. PCR amplification products were evaluated eletrophoretically on $1 \%$ agarose gels. Profile images were digitally recorded using the Molecular Imager Gel Documentation system (Kodak Digital System DC-120). The gel analysis was based on the similarity of the amplitypes generated from $A$. actinomycetemcomitans and F. nucleatum from different origins. Templates without DNA served as negative controls and were included in each AP-PCR.

\subsection{Statistical analyses}

The statistical analyses were performed by using Chi-squared and Kruskal-Wallis tests. Dendrograms were constructed by using the NTSYS software (Applied Biostatistics, Inc. Version 1.7).

\section{Results}

\subsection{Clinical findings}

A total of 240 subjects participated in this investigation. The general parameters of the individuals who were evaluated according to the criteria established are shown in Table 1. A positive relationship between age and pocket depth $(p<0.001)$ was observed, but the genera did not influence periodontal disease stage ( $p=0.409)$.

For culture assay, Aggregatibacter actinomycetemcomitans was isolated in $2(2.8 \%)$ individuals with gingivitis, 4 (5.3\%) with chronic periodontitis and 5 (5.26\%) healthy individuals; and $F$. nucleatum in 13 (18.6\%) of individuals with gingivitis, 20 (26.6\%) with chronic periodontitis and 19 (20\%) healthy. Both microorganisms were found in association in 5 (7.1\%) individuals with gingivitis, 9 (12\%) with chronic periodontitis and 3 (3.15\%) healthy individuals.

\subsection{Relationship between A. actinomycetemcomitans/F. nucleatum and periodontal disease stage}

To investigate the relationship between A. actinomycetemcomitans/F. nucleatum and clinical parameters, subgingival biofilm samples were assessed from the distinct groups. To ensure the quality of the data, we used two different methods to detect the presence of both microorganisms. Both culture and PCR assessment were not consistent in showing the prevalence of bacteria depending on the disease stage, with the exception to $F$. nucleatum in healthy individuals. Using PCR, A. actinomycetemcomitans appeared more prevalently in gingivitis and periodontitis groups and $F$. nucleatum did not exhibit any relationship with the depth of the pockets. However, considering a co-dependent frame, both bacteria were prevalent in chronic periodontitis individuals (Tables 1 and 2).

In a second set of experiments, we obtained quantitative measurements of $A$. actinomycetemcomitans and $F$. nucleatum from all of groups. As expected, the proportion of both pathogenic bacteria increased significantly in samples from gingivitis and chronic periodontitis individuals compared with healthy individuals (Table 2).

\subsection{Relation between biotyping and serotyping of A. actinomycetemcomitans}

A summary of results for biotyping and serotyping of A. actinomycetemcomitans from samples is presented in Table 3. Considering that different serotypes of $A$. actinomycetemcomitans may influence its ability of co-aggregation with $F$. nucleatum, we identified the biotypes and serotypes expressed by A. actinomycetemcomitans strains isolated from all individuals. Although the biotypes II and X and serotype c were observed in all groups, only strains expressing biotype II and serotype c were detected from the deeper pockets (Table 3; Fig. 1).

Further detailed analysis determined the presence of the toxicity gene in A. actinomycetemcomitans isolated from individuals with different periodontal conditions (Fig. 2). LTX promoter and the $l t x A$ gene were observed in $100 \%$ of the strains from periodontal individuals. Comparably, highly leukotoxic $A$. actinomycetemcomitans strains were detected in $82.8 \%$ of individuals with chronic periodontitis and minimally leukotoxic strains in $83 \%$ of healthy periodontal individuals. Significant percentages of $c d t A, c d t B$ and $c d t A B C$ genes were found in individuals with gingivitis and chronic periodontitis.

\subsection{Bacterial quantification}

The possible bacterial associations among other potential periodontopathogens were determined. Table 4 shows the presence of most evaluated bacteria and the predominance of $P$. intermedia and $P$. gingivalis varying from 0 to $6.2 \times 10^{5}$ copies in the three individual groups. T. forsythia, T. denticola, $P$. nigrescens, $D$. pneumosintes, $P$. endodontalis, E. faecalis and $A$. israelii were detected in ranges from 0 to $28.2 \times 10^{4}$ copies. 
Table 3

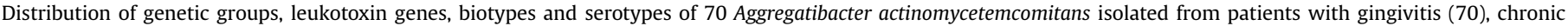
periodontitis (75), and healthy individuals (95).

\begin{tabular}{|c|c|c|c|c|c|c|c|c|c|c|c|c|c|c|c|c|c|c|c|}
\hline \multirow{2}{*}{$\begin{array}{l}\text { Clinical group } \\
\text { (No) }\end{array}$} & \multirow{2}{*}{$\begin{array}{l}\text { Isolates groups } \\
\text { (No) }\end{array}$} & \multirow{2}{*}{$\begin{array}{l}\text { Genetic groups } \\
\text { (No) }\end{array}$} & \multicolumn{8}{|c|}{ Genes } & \multicolumn{6}{|c|}{ Biotypes } & \multicolumn{3}{|c|}{ Serotypes } \\
\hline & & & $\begin{array}{l}530 \\
\text { bp }\end{array}$ & $\begin{array}{l}1022 \\
\text { bp }\end{array}$ & ltxA & $c d t A$ & $c d t B$ & $c d t C$ & $c d t A B C \mathrm{I}$ & & $\mathrm{II}^{\mathrm{a}}$ & IV & V & VI & $\mathrm{X}$ & $\mathrm{a}$ & b & $c^{a}$ & e \\
\hline 23 & 20 & 23 & 10 & 13 & 15 & 21 & 19 & 23 & 9 & $2(9 \%)$ & $\begin{array}{l}3 \\
(13 \%)\end{array}$ & $2(9 \%)$ & $\begin{array}{l}3 \\
(13 \%)\end{array}$ & $0(0 \%)$ & $\begin{array}{l}13 \\
(56 \%)\end{array}$ & $\begin{array}{l}2 \\
(8.7 \%)\end{array}$ & $0(0 \%)$ & $\begin{array}{l}11 \\
(47.8 \%)\end{array}$ & 10 \\
\hline 35 & 20 & 35 & 29 & 6 & 35 & 25 & 23 & 27 & 26 & $0(0 \%)$ & $\begin{array}{l}14 \\
(40 \%)\end{array}$ & $0(0 \%)$ & $0(0 \%)$ & $1(3 \%)$ & $\begin{array}{l}20 \\
(57 \%)\end{array}$ & $2(6 \%)$ & $\begin{array}{l}5 \\
(14 \%)\end{array}$ & $28(80 \%)$ & $0(0 \%)$ \\
\hline 12 & 11 & 11 & 1 & 10 & 11 & 1 & 3 & 3 & 3 & $0(0 \%)$ & $\begin{array}{l}7 \\
(58 \%)\end{array}$ & $0(0 \%)$ & $0(0 \%)$ & $0(0 \%)$ & $\begin{array}{l}5 \\
(42 \%)\end{array}$ & $0(0 \%)$ & $\begin{array}{l}2 \\
(17 \%)\end{array}$ & $10(83 \%)$ & $0(0 \%)$ \\
\hline
\end{tabular}

Value of $p<0.05$ was considered statistically significant by Chi-square test $\left(\chi^{2}\right)$.

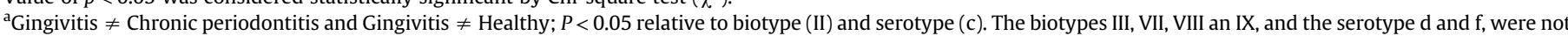
detected.

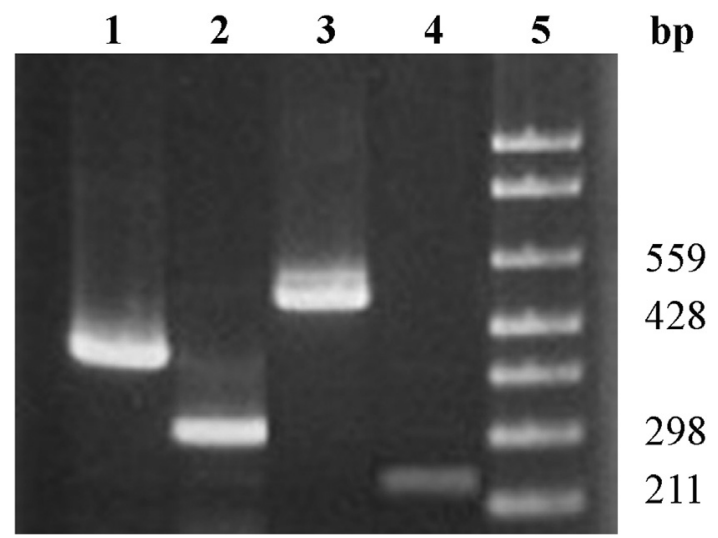

Fig. 1. Serotyping detection of Aggregatibacter actinomycetemcomitans by multiplex PCR. Lane 1. serotype A (individuals with gingivitis); Lane 2. serotype B (individuals with periodontitis); Lane 3. serotype C (individuals with periodontitis), and Lane 4. serotype $\mathrm{E}$ (individuals with gingivitis). Lane 5: $1 \mathrm{~Kb}$ Plus ladder (Invitrogen).

\subsection{Differences crossed from A. actinomycetemcomitans and F. nucleatum independent strains}

To obtain an overall estimation of bacterial genetic diversity within the clinical samples, AP-PCR was performed with oligonucleotide primers (OPA-3). The phylogenetic variations were clustered according to their similarity, as illustrated in the dendrograms. Consistent with previous data, most A. actinomycetemcomitans and F. nucleatum genetic variations were identified in individuals with gingivitis and chronic periodontitis. The AP-PCR method recorded 23 and 35 strains of
A. actinomycetemcomitans in 7 and 13 clinical isolates from gingivitis and periodontitis sites, respectively (Supplemental data Figs. 1 and 2). Of the total strains found, only 12 were detected in healthy individuals (Supplemental data - Fig. 3) and were grouped in 11 genetic groups with $75 \%$ of similarity.

For $F$. nucleatum, the OPA-5 primer identified 51 independent strains from 18 individuals with gingivitis, forming 9 genetic groups (78\% of similarity; Supplemental Fig. 4). The genetic variation was even higher in the chronic periodontitis group; recognizing 62 strains grouped in 20 genetic groups (86\% of similarity) from 29 individuals (Supplemental data - Fig. 5). Similar to A. actinomycetemcomitans, the frequencies of $F$. nucleatum strains detection was lower in healthy individuals than the other groups. Among the 40 strains identified, 16 genetic groups were formed with $85 \%$ of similarity (Supplemental data - Fig. 6).

\section{Discussion}

Periodontal disease constitutes a severe oral health problem worldwide [ 39 ]. Studies have reported that periodontal infections are not simply caused by biofilm accumulation on teeth surfaces but also by the interaction among several oral microbial community partners [ 40 ]. In this investigation, we extended our previous study [ $41-43$ ] by providing scientific evidence about the genetic diversity of two pathogenic bacteria and their relationship to periodontitis aggressiveness. Similarly to previous outcomes [13, 44,45 ], quantitative analyses between $A$. actinomycetemcomitans/ F. nucleatum and deeper probed cases showed significant differences in subjects with gingivitis and chronic periodontitis, compared to healthy subjects. Considering the ability of A. actinomycetemcomitans strains to secrete toxins involved in the

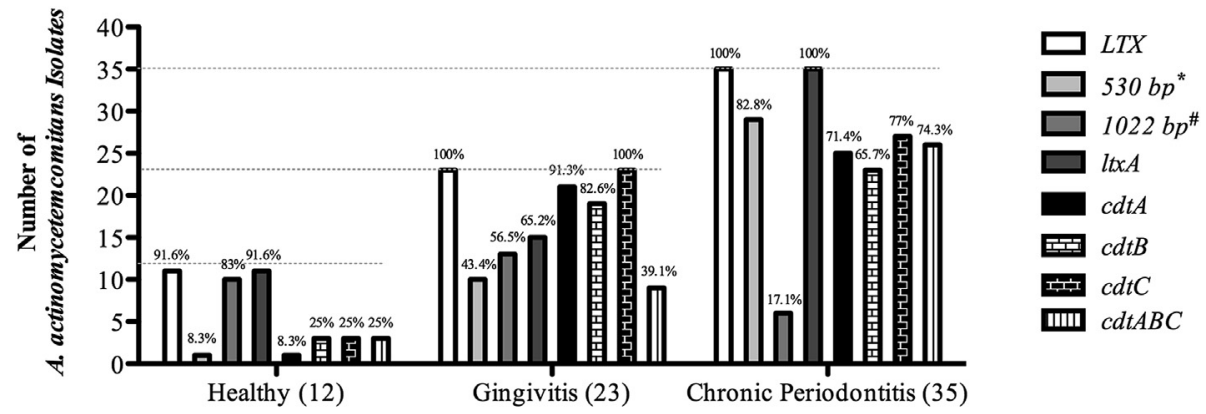

Gene Expression in A. actinomycetemcomitans

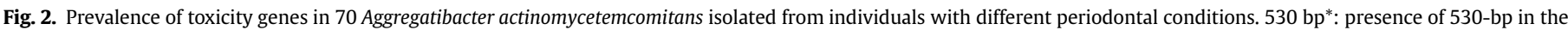
LTX gene operon. 1022 bp\#: presence of 1022-bp in the LTX gene operon. 
Table 4

Bacterial quantitative determination (qPCR) in patients with gingivitis, chronic periodontitis and healthy individuals.

\begin{tabular}{|c|c|c|c|c|c|}
\hline \multirow[t]{2}{*}{ Bacteria } & \multirow[t]{2}{*}{ Clinical group (No.) } & \multirow{2}{*}{$\frac{\text { Real-time PCR }}{\text { Positive samples (\%) }}$} & \multicolumn{2}{|c|}{ Number of copies $(\mathrm{DNA} / \mu \mathrm{L})$} & \multirow[t]{2}{*}{$p$ values } \\
\hline & & & Range of values & Median [interquartile deviation] & \\
\hline Porphyromonas gingivalis & $\begin{array}{l}\text { Gingivitis (70) } \\
\text { Periodontitis (75) } \\
\text { Healthy (95) }\end{array}$ & $\begin{array}{l}6897.1 \\
7498.6 \\
3536.8\end{array}$ & $\begin{array}{l}0-4.9 \times 10^{5} \\
0-5.5 \times 10^{5} \\
0-4 \times 10^{5}\end{array}$ & $\begin{array}{l}2.9 \times 10^{1}\left[1.3 \times 10^{2}\right] \\
6.7 \times 10^{3}\left[6.7 \times 10^{3}\right] \\
1.1 \times 10^{1}\left[4.6 \times 10^{1}\right]\end{array}$ & $<0.001^{*}$ \\
\hline Aggregatibacter actinomycetemcomitans & $\begin{array}{l}\text { Gingivitis (70) } \\
\text { Periodontitis (75) } \\
\text { Healthy (95) }\end{array}$ & $\begin{array}{l}5071.4 \\
6992.0 \\
6265.2\end{array}$ & $\begin{array}{l}0-1.14 \times 10^{8} \\
0-1.08 \times 10^{8} \\
0-9.43 \times 10^{4}\end{array}$ & $\begin{array}{l}2.2 \times 10^{2}\left[2.5 \times 10^{3}\right]^{\mathrm{a}} \\
1.5 \times 10^{5}\left[9.9 \times 10^{5}\right]^{\mathrm{a}} \\
0.6 \times 10^{1}\left[1.1 \times 10^{2}\right]\end{array}$ & $<0.002^{*}$ \\
\hline Fusobacterium nucleatum & $\begin{array}{l}\text { Gingivitis (70) } \\
\text { Periodontitis (75) } \\
\text { Healthy (95) }\end{array}$ & $\begin{array}{l}5274.2 \\
6890.6 \\
4951.5\end{array}$ & $\begin{array}{l}0-1.86 \times 10^{6} \\
0-3.98 \times 10^{6} \\
0-2.63 \times 10^{5}\end{array}$ & $\begin{array}{l}7.3 \times 10^{1}\left[2.2 \times 10^{3}\right]^{\mathrm{b}} \\
4.0 \times 10^{2}\left[3.8 \times 10^{4}\right]^{\mathrm{b}} \\
0.0\left[1.8 \times 10^{2}\right]\end{array}$ & $<0.001^{*}$ \\
\hline Porphyromonas endodontalis & $\begin{array}{l}\text { Gingivitis (70) } \\
\text { Periodontitis (75) } \\
\text { Healthy (95) }\end{array}$ & $\begin{array}{l}1318.5 \\
2128.0 \\
66.3\end{array}$ & $\begin{array}{l}0-12.2 \times 10^{4} \\
0-12.2 \times 10^{4} \\
0-2.8 \times 10^{5}\end{array}$ & $\begin{array}{l}0.0[0.0] \\
0.0\left[1.7 \times 10^{1}\right]^{\mathrm{a}} \\
0.0[0.0]\end{array}$ & $<0.05$ \\
\hline Prevotella intermedia & $\begin{array}{l}\text { Gingivitis (70) } \\
\text { Periodontitis (75) } \\
\text { Healthy (95) }\end{array}$ & $\begin{array}{l}4057.1 \\
5674.6 \\
4345.2\end{array}$ & $\begin{array}{l}0-5.9 \times 10^{5} \\
0-6.2 \times 10^{5} \\
0-5.2 \times 10^{5}\end{array}$ & $\begin{array}{l}1.2 \times 10^{1}\left[8.5 \times 10^{1}\right] \\
8.6 \times 10^{2}\left[8.6 \times 10^{3}\right]^{\mathrm{a}} \\
1.1 \times 10^{1}\left[4.6 \times 10^{1}\right]\end{array}$ & $<0.001^{*}$ \\
\hline Prevotella nigrescens & $\begin{array}{l}\text { Gingivitis (70) } \\
\text { Periodontitis (75) } \\
\text { Healthy (95) }\end{array}$ & $\begin{array}{ll}23 & 33.8 \\
31 & 41.3 \\
22 & 23.1\end{array}$ & $\begin{array}{l}0-14 \times 10^{4} \\
0-12.3 \times 10^{4} \\
0-28.2 \times 10^{4}\end{array}$ & $\begin{array}{l}0.0\left[8.2 \times 10^{1}\right] \\
0.0\left[3.2 \times 10^{1}\right] \\
0.0[0.0]\end{array}$ & $<0.216$ \\
\hline Tannerella forsythia & $\begin{array}{l}\text { Gingivitis (70) } \\
\text { Periodontitis (75) } \\
\text { Healthy (95) }\end{array}$ & $\begin{array}{l}5375.7 \\
6282.6 \\
6568.4\end{array}$ & $\begin{array}{l}0-15.6 \times 10^{5} \\
0-6.2 \times 10^{5} \\
0-5.2 \times 10^{5}\end{array}$ & $\begin{array}{l}2.6 \times 10^{2}\left[3.8 \times 10^{3}\right] \\
6.2 \times 10^{2}\left[5.5 \times 10^{4}\right]^{\mathrm{a}} \\
9.1 \times 10^{1}\left[2.4 \times 10^{2}\right]\end{array}$ & $<0.001^{*}$ \\
\hline Dialister pneumosintes & $\begin{array}{l}\text { Gingivitis (70) } \\
\text { Periodontitis (75) } \\
\text { Healthy (95) }\end{array}$ & $\begin{array}{l}6694.2 \\
7296.0 \\
8791.5\end{array}$ & $\begin{array}{l}0-25.9 \times 10^{3} \\
0-21.4 \times 10^{4} \\
0-24.0 \times 10^{4}\end{array}$ & $\begin{array}{l}1.0 \times 10^{6}\left[4 \times 10^{7}\right] \\
9.0 \times 10^{5}\left[2.0 \times 10^{7}\right] \\
5.7 \times 10^{5}\left[2.7 \times 10^{7}\right]\end{array}$ & $<0.507$ \\
\hline Treponema denticola & $\begin{array}{l}\text { Gingivitis (70) } \\
\text { Periodontitis (75) } \\
\text { Healthy (95) }\end{array}$ & $\begin{array}{l}6085.7 \\
6789.3 \\
6063.1\end{array}$ & $\begin{array}{l}0-18.1 \times 10^{4} \\
0-19.1 \times 10^{4} \\
0-17.3 \times 10^{3}\end{array}$ & $\begin{array}{l}1.3 \times 10^{4}\left[1.1 \times 10^{6}\right] \\
3.8 \times 10^{5}\left[8.0 \times 10^{6}\right] \\
5.4 \times 10^{2}\left[7.6 \times 10^{3}\right]\end{array}$ & $<0.05$ \\
\hline Enterococcus faecalis & $\begin{array}{l}\text { Gingivitis (70) } \\
\text { Periodontitis (75) } \\
\text { Healthy (95) }\end{array}$ & $\begin{array}{l}22.8 \\
45.3 \\
66.3\end{array}$ & $\begin{array}{l}0-16.3 \times 10^{4} \\
0-12.9 \times 10^{4} \\
0-12.5 \times 10^{4}\end{array}$ & $\begin{array}{l}0.0[0.0] \\
0.0[0.0] \\
0.0[0.0]\end{array}$ & $<0.605$ \\
\hline Actinomyces israelii & $\begin{array}{l}\text { Gingivitis (70) } \\
\text { Periodontitis (75) } \\
\text { Healthy (95) }\end{array}$ & $\begin{array}{l}3042.8 \\
5472.0 \\
3536.8\end{array}$ & $\begin{array}{l}0-11.4 \times 10^{4} \\
0-11.5 \times 10^{4} \\
0-11.5 \times 10^{4}\end{array}$ & $\begin{array}{l}0.0\left[6.7 \times 10^{1}\right] \\
5.6 \times 10^{2}\left[5.9 \times 10^{2}\right]^{a} \\
0.0\left[3.0 \times 10^{1}\right]\end{array}$ & $<0.001^{*}$ \\
\hline
\end{tabular}

*Values of $p<0.05$ were considered statistically significant values by the Kruskal-Wallis test.

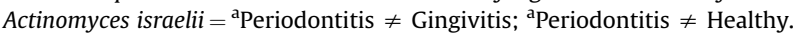

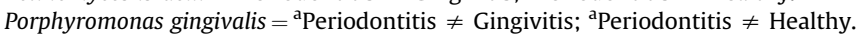

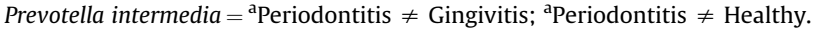

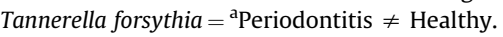

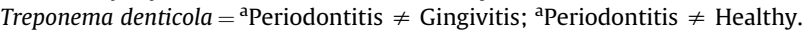

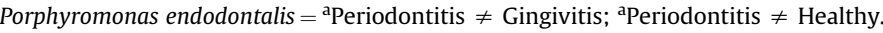

Aggregatibacter actinomycetemcomitan $={ }^{\mathrm{a}}$ Gingivitis $\neq$ Healthy and Periodontitis $\neq$ Healthy.

Fusobacterium nucleatum $={ }^{\mathrm{b}}$ Gingivitis $\neq$ Healthy and Periodontitis $\neq$ Healthy.

host immune response during the inflammatory process [16], we also demonstrated the distinctive surface structure gene expressions and related them to serotypes and probing depths.

A. actinomycetemcomitans and F. nucleatum are known as bacteria that are involved with periodontal diseases [21, 46 ]. The role of bacterial communication in the disease process outlines F. nucleatum as a key coadjuvant [ 22 ] that is able to co-aggregate with A. actinomycetemcomitans and intensifies damages around tooth-supporting tissues. This background knowledge corroborated our findings since a high prevalence $F$. nucleatum was observed in $90.6 \%$ of the total individuals with chronic periodontitis and $74.2 \%$ of the gingivitis group, while a lower percentage (51.5\%) was detected in healthy subjects. However, regarding the clinical parameters, although no significant interaction between age and pocket depth was supported by the scientific literature, our work has shown a positive relationship between both variables.

To better understand the factors involved in the pathogenesis of periodontal diseases, we investigated the association between serotypes and disease stage. Additionally, we related the virulence factor genes expressions from different $A$. actinomycetemcomitans to an early development of periodontal disease. The allotment patterns of A. actinomycetemcomitans serotypes were assessed by numerous studies and by different experimental designs [13, $43,44,47,48]$. Studies have suggested that highly pathogenic strains usually belong to serotype $\mathrm{b}$; therefore, there may be an association between serotype $b$ and aggressive periodontitis [15, 49, 50 ]. Conversely, our study showed heterogeneity of bacterial biotypes and no relationship between serotypes and pocket depths was 
observed. Indeed, a dominance of serotype c was observed in all groups, followed by serotypes a and b. Interesting, a recent study also did not detect serotype b even in relatively severe periodontal conditions among the subjects, and the authors interpreted the toxicity as being independent of serotypes [ 45 ]. Comparing our data with evidence from the literature and considering those studies were performed in different countries; we can suggest that gene expression is possibly driven by environmental conditions.

Taken into consideration the differences in $l t x$ and $c d t$ gene expressions among A. actinomycetemcomitans individual strains and their relationship with aggressive periodontitis [13, 51 ], further analyses were performed to correlate the presence of those genes with periodontal conditions. As expected, all strains of A. actinomycetemcomitans isolated from deep and shallow pockets had the ltx promoter and $91.6 \%$ of those bacterial species from healthy individuals were identified as carrying the $l t x$ gene. Additionally, although only $8.3 \%$ of A. actinomycetemcomitans strains from healthy individuals exhibited a highly leukotoxic phenotype, almost $92 \%$ of the total A. actinomycetemcomitans found in those individuals produced protein toxins $l t x A$. In other words, our results suggested that ItxA gene expression might not serve as a risk marker for disease stage. Actually, it was quite surprising that deletion of $530 \mathrm{bp}$ in the ltx promoter gene has been found in both periodontal conditions, and healthy and sick sites. With regard to additional important genes that were strongly associated with periodontal disease [17], our results revealed a high prevalence of the genes $c d t A, c d t B, c d t C$, and $c d t A B C$ in individuals with gingivitis and periodontal disease in contrast to the lower frequency observed in healthy conditions.

Wahasugui et al. [ 43 ] reported the presence of 64 A. actinomycetemcomitans strains as highly leukotoxic and only six strains as minimally leukotoxic. In addition, the presence of these leukotoxic strains had not association with the development of periodontitis, suggesting its transitory stage in oral cavity. It is possible that the evaluated strains here also showed this transitory characteristic in the analyzed population; since leukotoxic strains are associated with ecological and immunologic conditions of the examined individuals [15].

As mentioned above, the $c d t$ gene is an immunosuppressive factor and its high expression during advanced stage of periodontal disease has been corroborated in recent reports. However, the distribution of $c d t$ genes among the analyzed isolates did not show any serotype-dependent pattern, and it was not possible to demonstrate a specific correlation between them. These observations established the stage for a set of intriguing questions about which factors influence the expression of various toxins in bacterial cells of the subgingival biofilm in vivo in the presence of inflammation. Our results show a high frequency of the $c d t A, c d t B, c d t C$ and $c d t A B C$ genes in gingivitis and periodontitis individuals, and a low frequency in healthy individuals. These results are in accordance with data previously reported by Wahasugui et al. [ 43 ] who suggested that the absence of amplicons to these genes might be due to the deletion of the genes or the lack of homology with the primers. These authors also reported the presence of only one strain from healthy individual harboring the $c d t C$ gene suggesting the presence of an inactive gene.

To evaluate possible bacterial associations involved in the pathogenesis of periodontal disease, we also quantitatively determined the presence of other potential periodontal bacteria [ 34 , 52-58 ]. The predominance of $P$. intermedia and P. gingivalis, as well as the presence of $T$. forsythia, $T$. denticola, $P$. nigrescens, $D$. pneumosintes, $P$. endodontalis, E. faecalis and A. israelii in high values, allows us to suggest that there is some relationship among the presence of those bacteria including A. actinomycetemcomitans and $F$. nucleatum with the pathogenesis of periodontal disease. Since high numbers of these microorganisms were found in healthy individuals, it suggested that any host unbalance can modify the oral environment and develop infectious diseases.

Another important point to be discussed is the genetic variability observed in some pathogenic species as a reflex from pathogen-host-environment interactions. The high individual clonal diversity has been associated with advanced stage of periodontal disease and, as consequence of this mutation; the genetic types also may express different phenotypic characteristics and display an increase in virulence [ 59 ]. Consistent with the current information, our investigation identified, by a usefulness AP-PCR for fingerprinting pathogenic strains, most of genetic variations of A. actinomycetemcomitans and F. nucleatum in clinical isolates from individuals with gingivitis and chronic periodontitis. This is important information that will be addressed in future studies to uncover the bacterial genes involved in providing adaptation of the pathogens to the host environment, contributing to new target therapy development against resistant strains to antibiotics.

The results presented here strongly support a role of A. actinomycetemcomitans and F. nucleatum in advanced stage of periodontal disease. This study opens additional discussion about the role of the environment in the biotype and serotype prevalence depending on the periodontal conditions since the data revealed A. actinomycetemcomitans biotype II and serotype $\mathrm{c}$ in all clinical isolated samples. Subsequently, our data also showed no direct relationship between ltxA gene expression and leukotoxin gene 530-bp presence. This is in contrast to the $c d t$ gene, which predominated during the inflammatory disease process. Possible bacterial synergisms can occur in diseased and healthy sites.

\section{Acknowledgments}

Strains were kindly provided by Dr. Jeffrey Kaplan (Department of Oral Pathology, Biology and Diagnostic Sciences, New Jersey Dental School, Newark, New Jersey). The authors thank Mrs. Marcia Harumi for her technical support. This study was supported by CAPES Foundation and FAPESP 2013/13652-6.

Conflict of interest: The authors declare no conflict of interest.

\section{Appendix A. Supplementary data}

Supplementary data related to this article can be found at https://doi.org/10.1016/j.anaerobe.2018.05.015.

\section{References}

[1] S. Offenbacher, S.P. Barros, R.E. Singer, K. Moss, R.C. Williams, J.D. Beck, Periodontal disease at the biofilm-gingival interface, J. Periodontol. 78 (2007) 1911-1925.

[2] M.A. Taubman, T. Kawai, X. Han, The new concept of periodontal disease pathogenesis requires new and novel therapeutic strategies, J. Clin. Periodontol. 34 (2007) 367-369.

[3] M.A. Reynolds, Modifiable risk factors in periodontitis: at the intersection of aging and disease, Periodontol. 200064 (2014) 7-19.

[4] A. Boillot, B. El Halabi, G.D. Batty, H. Range, S. Czernichow, P. Bouchard, Education as a predictor of chronic periodontitis: a systematic review with metaanalysis population-based studies, PLoS One 6 (2011), e21508.

[5] S.S. Socransky, A.D. Haffajee, M.A. Cugini, C. Smith, R.L. Kent Jr., Microbial complexes in subgingival plaque, J. Clin. Periodontol. 25 (1998) 134-144.

[6] J.R. Cortelli, C.V. Roman-Torres, D.R. Aquino, G.C. Franco, F.O. Costa S.C. Cortelli, Occurrence of Aggregatibacter actinomycetemcomitans in Brazilians with chronic periodontitis, Braz. Oral Res. 24 (2010) 217-223.

[7] C.M. da Silva-Boghossian, R.M. do Souto, R.R. Luiz, A.P. Colombo, Association of red complex, A. actinomycetemcomitans and non-oral bacteria with periodontal diseases, Arch. Oral Biol. 56 (2011) 899-906. 
[8] E.G. Jardim Junior, J.M. Bosco, A.M. Lopes, L.F. Landucci, E.C. Jardim, S.R. Carneiro, Occurrence of Actinobacillus actinomycetemcomitans in patients with chronic periodontitis, aggressive periodontitis, healthy subjects and children with gingivitis in two cities of the state of Sao Paulo, Brazil, J. Appl. Oral Sci. 14 (2006) 153-156.

[9] M.J. Marin, N. Ambrosio, D. Herrera, M. Sanz, E. Figuero, Validation of a multiplex qPCR assay for the identification and quantification of Aggregatibacter actinomycetemcomitans and Porphyromonas gingivalis: in vitro and subgingival plaque samples, Arch. Oral Biol. 88 (2018) 47-53.

[10] O. Tsuzukibashi, M. Saito, T. Kobayashi, K. Umezawa, F. Nagahama, T. Hiroi, et al., A gene cluster for the synthesis of serotype g-specific polysaccharide antigen in Aggregatibacter actinomycetemcomitans, Arch. Microbiol. 196 (2014) 261-265.

[11] G. Rosen, I. Nisimov, M. Helcer, M.N. Sela, Actinobacillus actinomycetemcomitans serotype b lipopolysaccharide mediates coaggregation with Fusobacterium nucleatum, Infect. Immun. 71 (2003) 3652-3656.

[12] N. Suzuki, Y. Nakano, Y. Yoshida, D. Ikeda, T. Koga, Identification of Actinobacillus actinomycetemcomitans serotypes by multiplex PCR, J. Clin. Microbiol. 39 (2001) 2002-2005.

[13] N. Pahumunto, P. Ruangsri, M. Wongsuwanlert, S. Piwat, G. Dahlen, R. Teanpaisan, Aggregatibacter actinomycetemcomitans serotypes and DGGE subtypes in Thai adults with chronic periodontitis, Arch. Oral Biol. 60 (2015 $1789-1796$.

[14] A.S. Fabris, J.M. DiRienzo, M. Wikstrom, M.P. Mayer, Detection of cytolethal distending toxin activity and cdt genes in Actinobacillus actinomycetemcomitans isolates from geographically diverse populations, Oral Microbiol. Immunol. 17 (2002) 231-238.

[15] D. Haubek, A. Johansson, Pathogenicity of the highly leukotoxic JP2 clone of Aggregatibacter actinomycetemcomitans and its geographic dissemination and role in aggressive periodontitis, J. Oral Microbiol. 6 (2014).

[16] J.M. Brogan, E.T. Lally, K. Poulsen, M. Kilian, D.R. Demuth, Regulation of Actinobacillus actinomycetemcomitans leukotoxin expression: analysis of the promoter regions of leukotoxic and minimally leukotoxic strains, Infect. Immun. 62 (1994) 501-508.

[17] K.S. Tan, K.P. Song, G. Ong, Cytolethal distending toxin of Actinobacillus actinomycetemcomitans. Occurrence and association with periodontal disease, J. Periodontal. Res. 37 (2002) 268-272.

[18] G.N. Belibasakis, A. Johansson, Y. Wang, C. Chen, S. Kalfas, U.H. Lerner, The cytolethal distending toxin induces receptor activator of NF-kappaB ligand expression in human gingival fibroblasts and periodontal ligament cells, Infect. Immun. 73 (2005) 342-351.

[19] R.S. de Molon, V.I. Mascarenhas, E.D. de Avila, L.S. Finoti, G.B. Toffoli, D.M.P. Spolidorio, R.M. Scarel-Caminaga, S. Tetradis, J.A. Cirelli, Long-term evaluation of oral gavage with periodontopathogens or ligature induction of experimental periodontal disease in mice, Clin. Oral Investig. (2016) 1203-1216.

[20] R.S. de Molon, E.D. de Avila, A.V. Boas Nogueira, J.A. Chaves de Souza, M.J. Avila-Campos, C.R. de Andrade, J.A. Cirelli, Evaluation of the host response in various models of induced periodontal disease in mice, J. Periodontol. (2014) 465-477.

[21] S. Kurgan, S. Kansal, D. Nguyen, D. Stephens, Y. Koroneos, H. Hasturk, et al. Strain-specific impact of Fusobacterium nucleatum on neutrophil function, J. Periodontol. (2016) 1-17.

[22] C.W. Kaplan, R. Lux, S.K. Haake, W. Shi, The Fusobacterium nucleatum outer membrane protein RadD is an arginine-inhibitable adhesin required for interspecies adherence and the structured architecture of multispecies biofilm, Mol. Microbiol. 71 (2009) 35-47.

[23] P.I. Diaz, P.S. Zilm, A.H. Rogers, Fusobacterium nucleatum supports the growth of Porphyromonas gingivalis in oxygenated and carbon-dioxide-depleted environments, Microbiology 148 (2002) 467-472.

[24] A.J. Moller, Microbiological examination of root canals and periapical tissues of human teeth. Methodological studies, Odontol. Tidskr. 74 (Suppl I) (1966) $1-380$.

[25] M.J. Avila-Campos, G. Velasquez-Melendez, Prevalence of putative periodontopathogens from periodontal patients and healthy subjects in Sao Paulo, SP, Brazil, Rev. Inst. Med. Trop. Sao Paulo 44 (2002) 1-5.

[26] J. Slots, Salient biochemical characters of actinobacillus actinomycetemcomitans, Arch. Microbiol. 131 (1982) 60-67.

[27] J. Slots, Selective medium for isolation of Actinobacillus actinomycetemcomitans, J. Clin. Microbiol. 15 (1982) 606-609.

[28] R.E. Teixeira, E.N. Mendes, M.A. Roque de Carvalho, J.R. Nicoli, M. Farias Lde, P.P. Magalhaes, Actinobacillus actinomycetemcomitans serotype-specific genotypes and periodontal status in Brazilian subjects, Can. J. Microbiol. 52 (2006) 182-188.

[29] A. Ashimoto, C. Chen, I. Bakker, J. Slots, Polymerase chain reaction detection of 8 putative periodontal pathogens in subgingival plaque of gingivitis and advanced periodontitis lesions, Oral Microbiol. Immunol. 11 (1996) 266-273.

[30] M.J. Avila-Campos, C.T. Sacchi, A.M. Whitney, A.G. Steigerwalt, L.W. Mayer Arbitrarily primed-polymerase chain reaction for identification and epidemiologic subtyping of oral isolates of Fusobacterium nucleatum, J. Periodontol. 70 (1999) 1202-1208.

[31] C. Chen, J. Slots, Clonal analysis of Porphyromonas gingivalis by the arbitrarily primed polymerase chain reaction, Oral Microbiol. Immunol. 9 (1994) 99-103.

[32] C. Jauh-Hsun, T. Vinh, J.K. Davies, D. Figdor, Molecular approaches to the differentiation of Actinomyces species, Oral Microbiol. Immunol. 14 (1999) $250-256$.

[33] M. Kuboniwa, A. Amano, K.R. Kimura, S. Sekine, S. Kato, Y. Yamamoto, et al., Quantitative detection of periodontal pathogens using real-time polymerase chain reaction with TaqMan probes, Oral Microbiol. Immunol. 19 (2004) $168-176$.

[34] T.B. Lombardo Bedran, R.A. Marcantonio, R. Spin Neto, M.P. Alves Mayer, D. Grenier, L.C. Spolidorio, et al., Porphyromonas endodontalis in chronic periodontitis: a clinical and microbiological cross-sectional study, J. Oral Microbiol. 4 (2012).

[35] C. Nonnenmacher, A. Dalpke, J. Rochon, L. Flores-de-Jacoby, R. Mutters, K. Heeg, Real-time polymerase chain reaction for detection and quantification of bacteria in periodontal patients, J. Periodontol. 76 (2005) 1542-1549.

[36] M. Okamoto, N. Maeda, K. Kondo, K.P. Leung, Hemolytic and hemagglutinating activities of Prevotella intermedia and Prevotella nigrescens, FEMS Microbiol. Lett. 178 (1999) 299-304.

[37] S. Periasamy, N.I. Chalmers, L. Du-Thumm, P.E. Kolenbrander, Fusobacterium nucleatum ATCC 10953 requires Actinomyces naeslundii ATCC 43146 for growth on saliva in a three-species community that includes Streptococcus oralis 34, Appl. Environ. Microbiol. 75 (2009) 3250-3257.

[38] J.M. Williams, M. Trope, D.J. Caplan, D.C. Shugars, Detection and quantitation of E. faecalis by real-time PCR (qPCR), reverse transcription-PCR (RT-PCR), and cultivation during endodontic treatment, J. Endod. 32 (2006) 715-721.

[39] L.J. Jin, G.C. Armitage, B. Klinge, N.P. Lang, M. Tonetti, R.C. Williams, Global oral health inequalities: task group-periodontal disease, Adv. Dent. Res. 23 (2011) $221-226$.

[40] G.C. Armitage, P.B. Robertson, The biology, prevention, diagnosis and treatment of periodontal diseases: scientific advances in the United States, J. Am. Dent. Assoc. 140 (Suppl 1) (2009) 36S, 43S.

[41] E. Gaetti-Jardim Jr., T.C. Wahasugui, P.H. Tomazinho, M.M. Marques, V. Nakano, M.J. Avila-Campos, Distribution of biotypes and leukotoxic activity of Aggregatibacter actinomycetemcomitans isolated from Brazilian patients with chronic periodontitis, Braz. J. Microbiol. 39 (2008) 658-663.

[42] E.M. Vieira, S.A. Raslan, T.C. Wahasugui, M.J. Avila-Campos, V. Marvulle, E. Gaetti-Jardim Junior, Occurrence of aggregatibacter actinomycetemcomitans in brazilian indians from umutina reservation, mato grosso, Brazil, J. Appl. Oral Sci. 17 (2009) 440-445.

[43] T.C. Wahasugui, V. Nakano, R.M. Piazza, M.J. Avila-Campos, Phenotypic and genotypic features of Aggregatibacter actinomycetemcomitans isolated from patients with periodontal disease, Diagn. Microbiol. Infect. Dis. 75 (2013) 366-372.

[44] C. Chen, T. Wang, W. Chen, Occurrence of Aggregatibacter actinomycetemcomitans serotypes in subgingival plaque from United States subjects, Mol. Oral Microbiol. 25 (2010) 207-214.

[45] Y. Li, H. Guo, X. Wang, Y. Lu, C. Yang, P. Yang, Coinfection with Fusobacterium nucleatum can enhance the attachment and invasion of Porphyromonas gingivalis or Aggregatibacter actinomycetemcomitans to human gingival epithelial cells, Arch. Oral Biol. 60 (2015) 1387-1393.

[46] H. Chahboun, M.M. Arnau, D. Herrera, M. Sanz, O.K. Ennibi, Bacterial profile of aggressive periodontitis in Morocco: a cross-sectional study, BMC Oral Health 15 (2015) 25.

[47] S. Asikainen, C. Chen, J. Slots, Actinobacillus actinomycetemcomitans genotypes in relation to serotypes and periodontal status, Oral Microbiol. Immunol. 10 (1995) 65-68.

[48] M. Yamamoto, T. Nishihara, T. Koseki, T. He, K. Yamato, YJ. Zhang et al., Prevalence of Actinobacillus actinomycetemcomitans serotypes in Japanese patients with periodontitis, J. Periodontal. Res. 32 (1997) 676-681.

[49] S. Melgar-Rodriguez, J. Diaz-Zuniga, C. Alvarez, L. Rojas, G. Monasterio, P. Carvajal, et al., Serotype b of Aggregatibacter actinomycetemcomitans increases osteoclast and memory T-lymphocyte activation, Mol. Oral Microbiol. 31 (2016) 162-174.

[50] M. Minguez, O.K. Ennibi, X. Pousa, L. Lakhdar, L. Abdellaoui, M. Sanchez, et al., Characterization of A. actinomycetemcomitans strains in subgingival samples from periodontitis subjects in Morocco, Clin. Oral Invest. 20 (2016) $1809-1818$

[51] N. Pahumunto, P. Ruangsri, M. Wongsuwanlert, S. Piwat, G. Dahlen, R. Teanpaisan, Virulence of Aggregatibacter actinomycetemcomitans serotypes and DGGE subtypes isolated from chronic adult periodontitis in Thailand, Anaerobe 36 (2015) 60-64.

[52] A.V. Colombo, G.M. Barbosa, D. Higashi, G. di Micheli, P.H. Rodrigues, M.R. Simionato, Quantitative detection of Staphylococcus aureus, Enterococcus faecalis and Pseudomonas aeruginosa in human oral epithelial cells from subjects with periodontitis and periodontal health, J. Med. Microbiol. 62 (2013) 1592-1600.

[53] C.T. Ferraro, C. Gornic, A.S. Barbosa, R.J. Peixoto, A.P. Colombo, Detection of Dialister pneumosintes in the subgingival biofilm of subjects with periodontal disease, Anaerobe 13 (2007) 244-248.

[54] K.V. Hiranmayi, K. Sirisha, M.V. Ramoji Rao, P. Sudhakar, Novel pathogens in periodontal microbiology, J. Pharm. BioAllied Sci. 9 (2017) 155-163. 
[55] P.S. Kumar, A.L. Griffen, J.A. Barton, B.J. Paster, M.L. Moeschberger, E.J. Leys, New bacterial species associated with chronic periodontitis, J. Dent. Res. 82 (2003) 338-344.

[56] P.J. Perez-Chaparro, J.A. McCulloch, E.M. Mamizuka, A. Moraes, M. Faveri, L.C. Figueiredo, et al., Do different probing depths exhibit striking differences in microbial profiles? J. Clin. Periodontol. 45 (2018) 26-37.

[57] R. Souto, A.P. Colombo, Prevalence of Enterococcus faecalis in subgingival biofilm and saliva of subjects with chronic periodontal infection, Arch. Oral Biol. 53 (2008) 155-160.

[58] T. Tran, M.J. Flynn, C. Chen, J. Slots, Porphyromonas endodontalis in subgingival plaque, Clin. Infect. Dis. 25 (Suppl 2) (1997) S222-S223.

[59] R.J. Genco, B.G. Loos, The use of genomic DNA fingerprinting in studies of the epidemiology of bacteria in periodontitis, J. Clin. Periodontol. 18 (1991) 396-405. 